\title{
Acute ischemic stroke within the area of MCA from ICA thrombosis complicating moderate COVID-19 infection
}

\author{
Ewa Kurys-Denis ${ }^{1, A-D, F \oplus}$, Andrzej Prystupa ${ }^{2, E-F \oplus}$, Jarosław Sak ${ }^{3, D-F \oplus}$ \\ ${ }^{1}$ 2nd Department of Radiology, Medical University, Lublin, Poland \\ 2 Department of Internal Medicine, Medical University, Lublin, Poland \\ ${ }^{3}$ Chair and Department of Humanities and Social Medicine, Medical University, Lublin, Poland \\ A - Research concept and design, B - Collection and/or assembly of data, C - Data analysis and interpretation, \\ $D$ - Writing the article, E-Critical revision of the article, $F$ - Final approval of article
}

\begin{abstract}
Kurys-Denis E, Prystupa A, Sak J. Acute ischemic stroke within the area of MCA from ICA thrombosis complicating moderate COVID-19
\end{abstract} infection. J Pre-Clin Clin Res. 2021; 15(1): 30-33. doi: 10.26444/jpccr/132590

\begin{abstract}
Coronavirus disease 2019 (COVID-19), caused by the severe acute respiratory syndrome-coronavirus type 2 (SARS-Cov-2), injures multiple organs including the central and peripheral nervous system. We report the case of a 68-year-old patient diagnosed with COVID-19 infection in its moderate form who, 1 week after the onset of respiratory symptoms, developed a large acute ischemic stroke (AIS) in the area of the left middle cerebral artery (LMCA). The case shows that large artery stroke can occur even in moderate forms of COVID-19, and stresses the need for correct coagulation management. The source of cerebral stroke should also be sought by cervical computed tomography angiography (CTA) from the level of the aortic arch, and not only covering the cerebral vessels as thrombo-embolic events may appear already in large cervical vessels, even in mild forms of the disease.
\end{abstract}

\section{Keywords}

acute ischemic stroke, COVID-19, MCA, chest X-ray, brain CT angiography, LICA

\section{INTRODUCTION}

Coronavirus disease 2019 (COVID-19), caused by the severe acute respiratory syndrome-coronavirus type 2 (SARSCov-2) [1], has reached pandemic status and infected over 80 million people worldwide in the 12 months since its discovery. COVID-19, a highly contagious disease, was thought initially to damage mainly the respiratory system. Today, we know that SARS-Cov-2 causes injury to multiple organs, include the central and peripheral nervous systems (CNS, PNS). Neurological manifestations of CNS invasion include encephalopathy, encephalomyelitis, encephalitis, meningitis, ischemic and hemorrhagic stroke, venous sinus thrombosis or endothelialitis. Symptoms of PNS involve mostly the dysfunction of smell and taste, muscle injury or Guillain-Barré syndrome variants. In Wuhan, China, neurological symptoms were observed in up to $36 \%$ of COVID-19 patients: $25 \%$ had CNS symptoms, mostly dizziness (17\%), headache (13\%) and impaired consciousness (7.5\%). Acute cerebrovascular disease occurred in only $3 \%$ of hospitalized patients, with further ataxia or seizures appearing in less than $1 \%$ of patients [2].

We hereby report the case of a 68-year-old man diagnosed with COVID-19 infection in its moderate form who, 1 week after the onset of respiratory symptoms, developed a large acute ischemic stroke (AIS) in the area of the left middle cerebral artery (LMCA).

\section{CASE REPORT}

The initial symptoms presented by the patient included fever and dry cough. The medical history included controlled arterial hypertension. No previous treatment or other vascular risks factors were noted. The patient spent 5 days at home in isolation with typical symptoms after COVID-19 out-patient diagnosis. He was referred to our hospital with a progressing cough and decreasing saturation for oxygen therapy. At admission, laboratory findings showed multiple risk factors for poor clinical outcome: high levels of Interleukin-6 (Il-6), ferritin, C-reactive protein (CRP), limfopenia, with normal levels of procalcitonin, red blood cell (RBC) and neutrophils (Tab. 1). D-dimer level and platelet count were normal. Chest $\mathrm{X}$-ray showed classical diffuse changes observed in SARSCov-2 infections (Fig. 1).

Table 1. Biochemical characteristic of the patient

\begin{tabular}{lccc}
\hline Blood values at admission & & & \\
\hline RBC & $3,11 \mathrm{M} / \mathrm{uL}$ & HGB & $9.5 \mathrm{~g} / \mathrm{dl}$ \\
\hline WBC & $7.34 \mathrm{~K} / \mathrm{uL}$ & LYM & $0.22 \mathrm{~K} / \mathrm{uL}$ \\
\hline NEU & $7 \mathrm{~K} / \mathrm{uL}$ & Ferritin & $723 \mathrm{ug} / \mathrm{l}$ \\
\hline II-6 & $46.87 \mathrm{pg} / \mathrm{ml}$ & CRP & $181 \mathrm{mg} / \mathrm{l}$ \\
\hline Procalcitonin & $0.13 \mathrm{ng} / \mathrm{ml}$ & D-Dimer & $152 \mathrm{ng} / \mathrm{ml}$ \\
\hline
\end{tabular}

Note: RBC - red blood cells; HGB - hemoglobin; WBC - white blood cells; LYM - lymphocytes; NEU - neutrophils; II-6 - Interleukin-6; CRP - C-reactive protein

Three days later, the patients developed acute aphasia and right progressive hemiparesis. Brain computer tomography (CT) and CT angiography (CTA) performed 4 hours after the onset of clinical symptoms, showed subtle hypoattentuation 


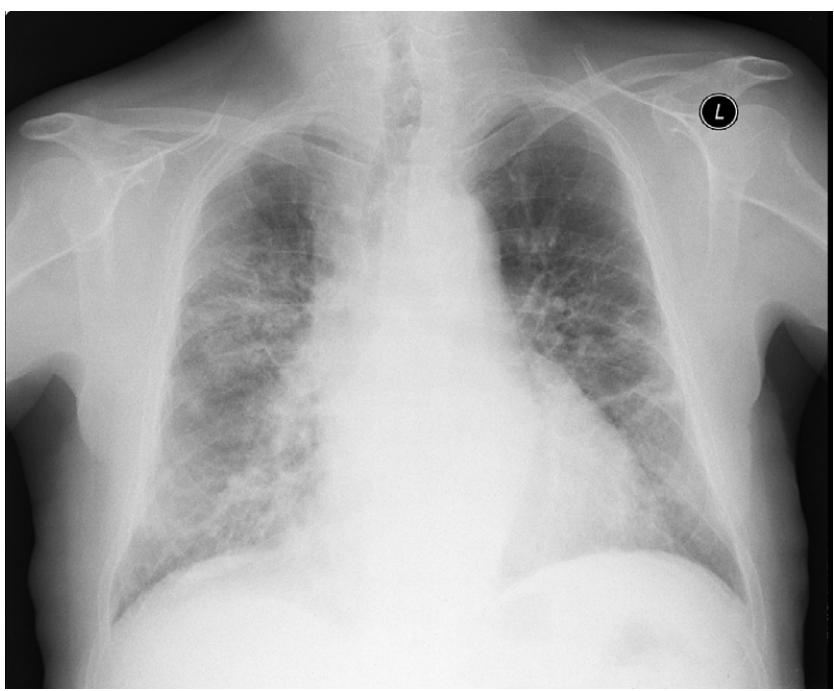

Figure 1. Chest X-ray at admission showed classical diffuse interstitial opacities in both lungs with scattered ground-glass opacifications, observed in SARS-Cov-2 infections. Local consolidations can also be seen in the lower part of the right lung.

within the left putamen, globus pallidus and insula, consistent with cerebral ischemic infarct (Fig. 2A, 2B). CTA depicted a large occlusive thrombus at the base of the left internal carotid artery (LICA) and multiple smaller thromboses in the distal part of LICA, as well the proximal part of LMCA (Fig. 2C, 2D, 3). Distal branches of LMCA were filled by the collateral circulation. The patient was sent to a specialized unit at another hospital for immediate invasive thrombectomy for stroke disease intervention, where the invasion treatment was performed with success. To the best of our knowledge, this

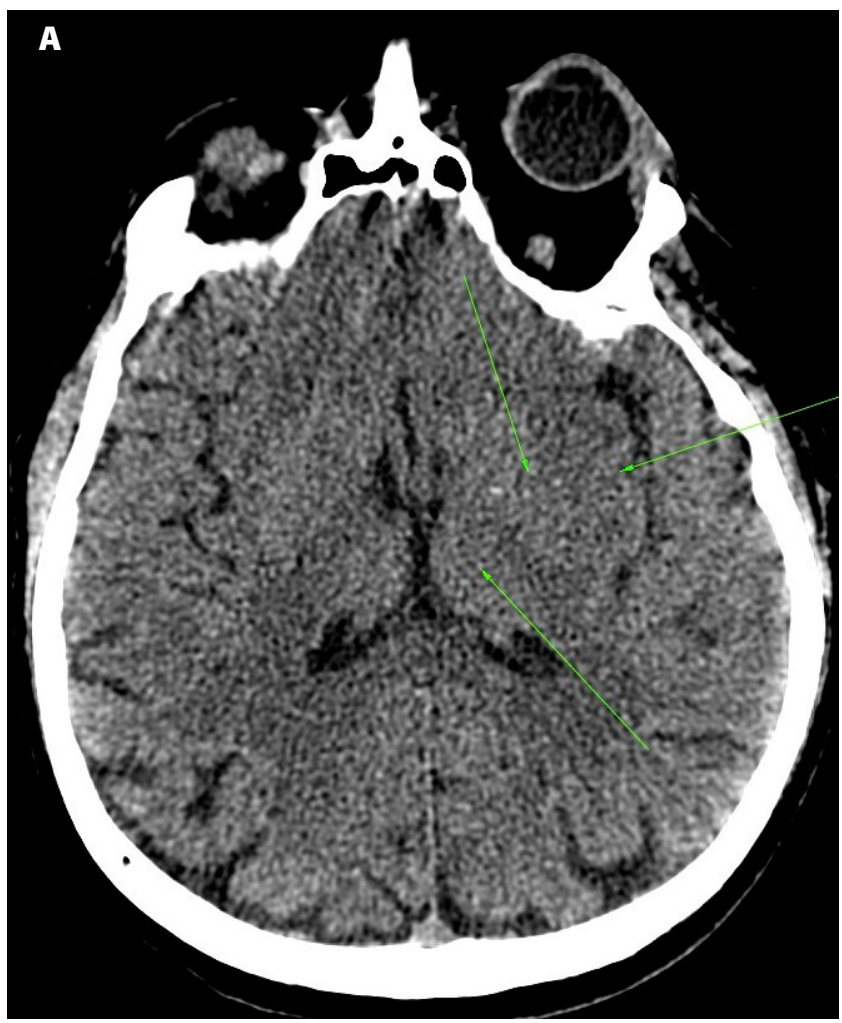

Figure 2. A,B.CT scan before (2A) and after the contrast administration (2B) shows subtle hypoattentuation within left putamen, globus pallidus and insula (arrows), consistent with cerebral ischemic infarct. Commencing edema in the whole territory of LMCA can be seen. Motion artifacts caused by difficulties in breathing
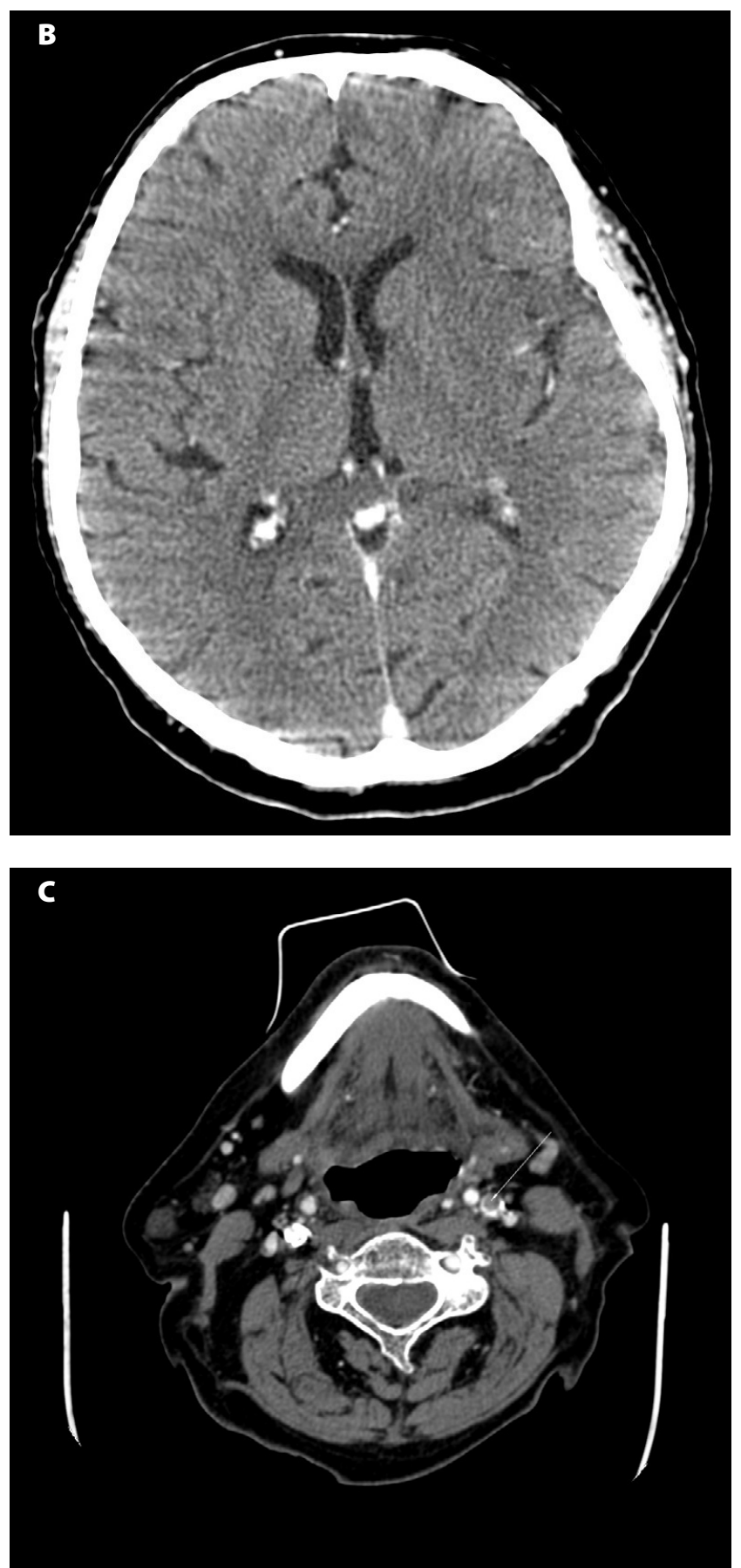

Figure $2 \mathrm{C}$. CTA image shows large $5 \mathrm{~mm}$ occlusive thrombus at the base of the left internal carotid artery (LICA) (arrow)

is the first moderate Covid-19 case in Poland presenting in the low cervical location of a thrombus caused by an acute MCA stroke.

\section{DISCUSSION}

The new disease entity, COVID-19, was first identified in China in December 2019 [3] as being caused by severe acute respiratory syndrome coronavirus 2 (SARS-CoV-2) [1]. Initially, it was thought to be an acute disease with no very serious long-term effects on convalescents. However, Urciuoli and Guerriero demonstrated that the dissipation 


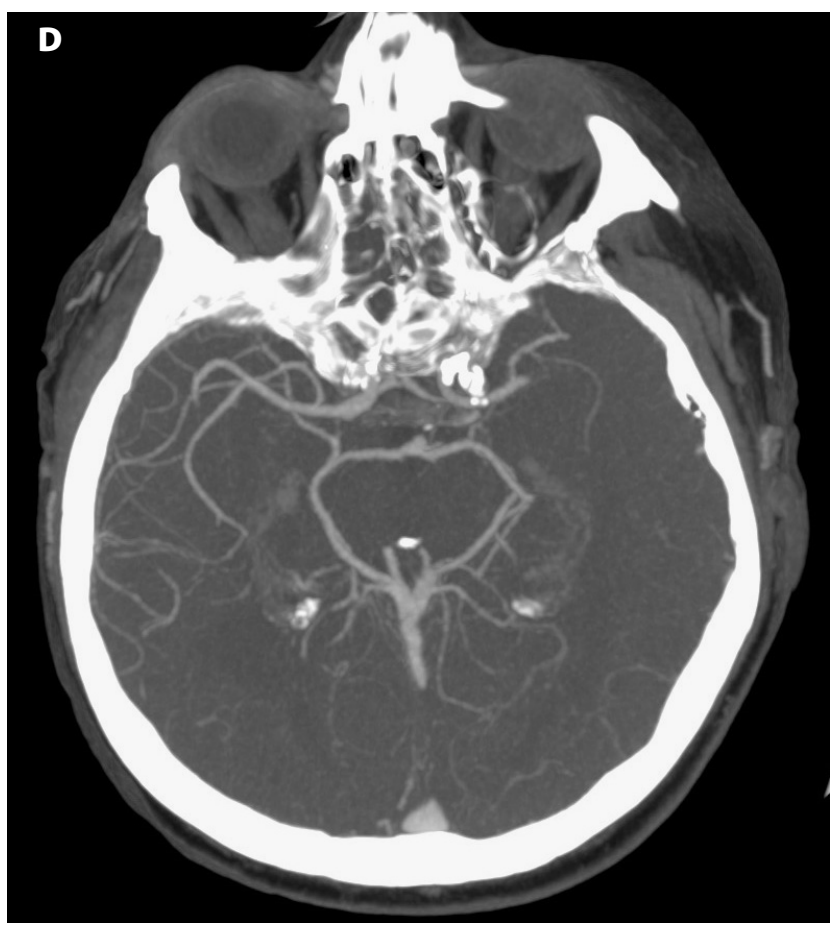

Figure 2D. MIR image depicting further smaller thromboses and cutt-off image in the proximal part of LMCA. Note the big lack of circulation in the territory of LMCA

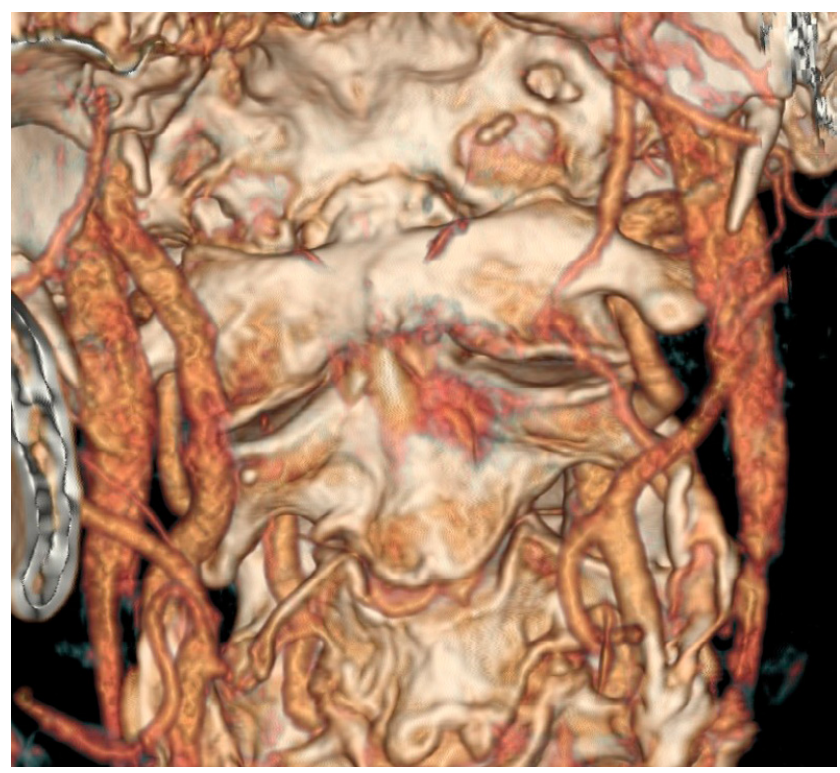

Figure 3. The 3D reconstruction showing sudden narrowing and the lack of flow in the LICA. Note large calcified plaques in the internal and common cervical arteries indicative of long-lasting atherosclerosis

stage could last not only $2-3$ weeks from onset of symptoms (chest CT) $[4,5]$, but for months after the clinical resolution of the disease [5]. Initially, the effects of the SARS-CoV-2 on organs other than the respiratory system were also not noticed. In 2020, medical knowledge about the course of COVID-19 underwent a similar dynamic change as the pandemic spread worldwide. The very serious complications, other than respiratory, have been noticed along with the dynamically increasing number of clinical observations of COVID-19. One such complication was acute ischemic stroke (AIS), which appeared in only $2.5 \%$ of hospitalized patients in Milan, Italy [6]. The reasons for neurological complications in Covid-19 are still hypothetical, including hyperinflammatory and hypercoagulable states induced by SARS-Cov-2, immune mediated reaction, or direct invasion of the virus into CNS. Coagulopathy has been reported to correlate with the severity of respiratory failure with venous thromboembolism as the most common consequence seen in severe forms of the disease (up to $6.6 \%$ of all hospitalized patients) [7]. Cerebral stroke has also been observed, although mostly in severe forms of the disease (5.7\% of critical patients), and rarely in mild forms of COVID-19 (0.8\% of patients) $[6,7]$. Relatively rare cerebrovascular and cardiovascular complications are highly associated with the outcome and mortality in COVID-19 patients, and therefore constitute important risk factors that should be strictly monitored $[2,6-9]$. The presented case shows that large artery stroke can occur even in moderate forms of COVID-19, and stresses the need for correct coagulation management. Zamboni suggested that D-dimer and troponin levels appear to be very powerful prognostic markers, signalling the need for earlier interventions in order to minimize thromboembolism [10]. Coagulopathy in such patients may lead to a large-vessel arterial thrombosis more often than previously thought. In the presented case, D-dimer level, platelet count, as well as coagulopathy indices, were normal at admission. However, the patient presented other laboratory findings that today are considered risk factors for poor clinical outcome in COVID-19: high levels of Il-6, ferritin, CRP, limfopenia, with normal levels of procalcitonin, $\mathrm{RBC}$ and neutrophils. Such a combination of abnormal laboratory findings should sensitize doctors and make them aware of a possible poor outcome. The patient in this case developed a sudden onset of serious coagulopathy only 3 days later.

Furthermore, the source of cerebral stroke should be sought also by cervical CTA from the level of the aortic arch, and not only covering the cerebral vessels as thromboembolic events may appear already in large cervical vessels, even in mild forms of the disease [12].

\section{REFERENCES}

1.Zhu N, Zhang D, Wang W et al. China Novel Coronavirus Investigating and Research Team. A Novel Coronavirus from Patients with Pneumonia in China, 2019. N Engl J Med. 2020 Feb 20;382(8):727-733. doi: 10.1056/ NEJMoa2001017.

2. Koralnik IJ, Tyler KL. COVID-19: A Global Threat to the Nervous System. Ann Neurol. 2020 Jul;88(1):1-11. doi: 10.1002/ana.25807.

3. Lu H, Stratton CW, Tang YW. Outbreak of pneumonia of unknown etiology in Wuhan, China: The mystery and the miracle. J Med Virol. 2020 Apr;92(4):401-402. doi: 10.1002/jmv.25678.

4. Jin $\mathrm{YH}, \mathrm{Cai} \mathrm{L}$, Cheng ZS, et al. A rapid advice guideline for the diagnosis and treatment of 2019 novel coronavirus (2019-nCoV) infected pneumonia (standard version). Mil Med Res. 2020 Feb 6;7(1):4. doi: 10.1186/s40779-020-0233-6. PMID: 32029004; PMCID: PMC7003341..

5. Urciuoli L, Guerriero E. Chest CT Findings after 4 Months from the Onset of COVID-19 Pneumonia: A Case Series. Diagnostics (Basel). 2020 Nov 3;10(11):899. doi: 10.3390/diagnostics10110899.

6. Lodigiani C, Iapichino G, Carenzo L, et al. Venous and arterial thromboembolic complications in COVID-19 patients admitted to an academic hospital in Milan, Italy. Thromb Res. 2020 Jul;191:9-14. doi: 10.1016/j.thromres.2020.04.024.

7. Fara MG, Stein LK, Skliut M, et al. Macrothrombosis and stroke in patients with mild Covid-19 infection. J Thromb Haemost. 2020 Aug;18(8):2031-2033. doi: 10.1111/jth.14938.

8. Viguier A, Delamarre L, Duplantier J, et al. Acute ischemic stroke complicating common carotid artery thrombosis during a severe COVID-19 infection. J Neuroradiol. 2020 Sep;47(5):393-394. doi: 10.1016/j.neurad.2020.04.003. 
9. Beyrouti R, Adams ME, Benjamin L, et al. Characteristics of ischaemic stroke associated with COVID-19. J Neurol Neurosurg Psychiatry. 2020 Aug;91(8):889-891. doi: 10.1136/jnnp-2020-323586.

10.Zamboni P. COVID-19 as a Vascular Disease: Lesson Learned from Imaging and Blood Biomarkers. Diagnostics (Basel). 2020 Jun 29;10(7):440. doi: 10.3390/diagnostics10070440.
11. Tan YK, Goh C, Leow AST, et al. COVID-19 and ischemic stroke: a systematic review and meta-summary of the literature. J Thromb Thrombolysis. 2020 Oct;50(3):587-595. doi: 10.1007/s11239-02002228-y.

12. John S, Kesav P, Mifsud VA, et al. Characteristics of Large-Vessel Occlusion Associated with COVID-19 and Ischemic Stroke. AJNR Am J Neuroradiol. 2020 Dec;41(12):2263-2268. doi: 10.3174/ajnr.A6799. 